\section{Summary}

A series of 200 cases of kerosene ingestion is reviewed.

Clinical and radiological findings suggest that the most significant complication is pulmonary damage following aspiration. Systemic effects of kerosene absorption appeared to be of little practical importance.

A standard conservative regime of prophylactic penicillin, without gastric lavage, was employed. The mortality rate was $0.5 \%$.

A review of experimental reports and clinical findings indicate that treatment should be conservative, and that gastric lavage is contraindicated in the management of this condition.

We should like to express our thanks to Dr. P. E. S. Palmer, senior radiologist, Mpilo Hospital, for the $x$-ray report ; and to
Dr. M. Webster, Secretary for Health, Southern Rhodesia, for permission to publish.

\section{REFERENCES}

Brit. med. 7., 1963, 1, 208.

Caffey, J. P. (1961). Paediatric X-ray Diagnosis, 4th ed., p. 322. Year Book Medical Publishers, Chicago.

Deichmann, W. B., Kitzmiller, K. V., Witherup, B. S., and Johansmann, R. (1944). Ann. intern. Med., 21, 803.

Gerarde, H. W. (1959). Toxicol. appl. Pharmacol., 1, 462.

Kossick, P. (1951). S. Afr. med. 7., 35, 112.

Mayock, R. L., Bozorgnia, N., and Zinsser, H. F. (1961). Ann. intern. Med., 54, 559.

McDonald, R. (1961). S. Afr. med. f., 35, 21.

Richardson. J. A., and Pratt-Thomas, H. R. (1951). Amer. F. med. Sci., 221, 531 .

Spector, W. S. (1956). Handbook of Toxicology, vol. 1, “Acute Toxicities." Saunders, Philadelphia. Quoted by Gerarde (1959).

\title{
Cervical Phimosis
}

\author{
PREMA M. NAIDU,* M.D., F.R.C.S.ED., F.R.C.O.G. ; SUVARNA RAMASWAMY, $\dagger$ M.D. \\ SUNDARI KRISHNA, $\ddagger$ M.D.
}

Brit. med. F., 1964, 2, 30-31

The developmental origin of any transverse occluding membrane in the vagina is a much-disputed subject. Rubin (1944) first used the term " cervical phimosis" to describe a condition of a transverse vaginal septum situated immediately below the cervix. This septum has a small opening through which menstruation occurs and conception, occasionally, takes place. In a typical example of this congenital abnormality there is an annular fold of vaginal wall which appears to cover the entire cervix during rest but would retract when the cervix is pulled upon, as in Case 4 below.

\section{Case Reports}

Four cases with congenital transverse septa of the cervical phimosis type were met with in this hospital during a sixmonths period from September, 1960.

Case 1.-The patient, aged 19, was admitted to hospital in September 1960 with a history of dysmenorrhoea since her menarche five years previously. Her menstrual cycles were regular. She had been married for three years. She was a normally developed young woman of average build. Pelvic examination revealed a transverse septum in the upper part of the vagina immediately below the cervix. There was a small opening in the septum a little to the left side admitting a probe. On rectal examination the uterus was felt; it was normal in size. A diagnosis of cervical phimosis was obvious. Incisions were made on each side of the septum starting from the central opening. This resulted in bilateral wing-shaped raw areas, which were closed with interrupted linen sutures. The result was satisfactory.

Case 2.-This patient, aged 25, was admitted in November 1960 with a history of four months' amenorrhoea. Her menstrual cycles had been regular. Caesarean section had been performed elsewhere six years previously, presumably for non-dilatation of the cervix. Vaginal examination revealed a transverse septum in the upper part

* Professor of Obstetrics and Gynaecology, Institute of Obstetrics and Gynaecology, Government Maternity Hospital, Hyderabad, India.

t Assistant Professor, Institute of Obstetrics and Gynaecology, Government Maternity Hospital, Hyderabad, India.

‡ Gynaecological Registrar, Institute of Obstetrics and Gynaecology, Government Maternity Hospital, Hyderabad, India. of the vagina about $1 \mathrm{~cm}$. below the cervix with a small opening almost in its centre. This septum was treated by lateral incisions as in Case 1. The patient became pregnant again and delivered spontaneously. No septum could be palpated or delineated in the post-natal period.

Case 3.-A primigravida, aged 22, was seen in labour in December 1960. During the course of a vaginal examination a transverse septum at the upper third of the vagina was noted. There was a central opening admitting a finger, and the foetal head was stretching the septum. Transverse incision of the septum was followed by spontaneous delivery of a live term infant. At a follow-up examination a year later a cicatricial ring was noted about $2 \mathrm{~cm}$. below the cervix. No definitive treatment was carried out.

Case 4.- The patient, aged 28, was admitted on 4 March 1961 for investigation of infertility. Her periods had been regular, but she gave a history of dysmenorrhoea of the spasmodic type. She had failed to conceive even after ten years of married life. On examination the vagina was found to be of normal depth. The uterus was retroverted and normal in size. There was a fleshy annular septum in the upper third of the vagina which behaved like the shutter of a camera when traction was applied on to the cervix (see Fig.). Treatment was not thought necessary.

\section{Discussion}

A complete atresia or a transverse occluding membrane at the lower levels of the vagina resulting in cryptomenorrhoea is seen fairly often; but the condition of a transverse incomplete septum, with a small opening, situated across the upper vagina and aptly known as "phimosis of the cervix" is less common. This condition is likely to be mistaken for congenital absence of cervix and uterus with a normal vaginal vault as indicated by Jeffcoate (1957). Minor degrees of this deformity appearing as an annular constriction of the upper vagina may be recognized more often if this condition is kept in mind when cases of infertility or dyspareunia are being examined.

It is now widely accepted that the upper four-fifths of the vagina is developed from the Müllerian ducts and the lower one-fifth from the sino-vaginal bulbs. Certain anomalies at the lower levels of the vagina support this composite origin 
(Monie and Sigardson, 1950). On the other hand, Warner and Mann (1955) believe that in most instances of "imperforate hymen" the cause is probably the persistence of the group of central epithelial cells in the membrane which ordinarily degenerate during the course of development. Another explanation put forward by them is that of an inflammatory reaction during infancy or intrauterine life causing a cicatrix of this area and resulting in development of the vaginal septum.

However acquired, vaginal septa not unlike phimosis of the cervix were also seen by us in patients who gave a history of

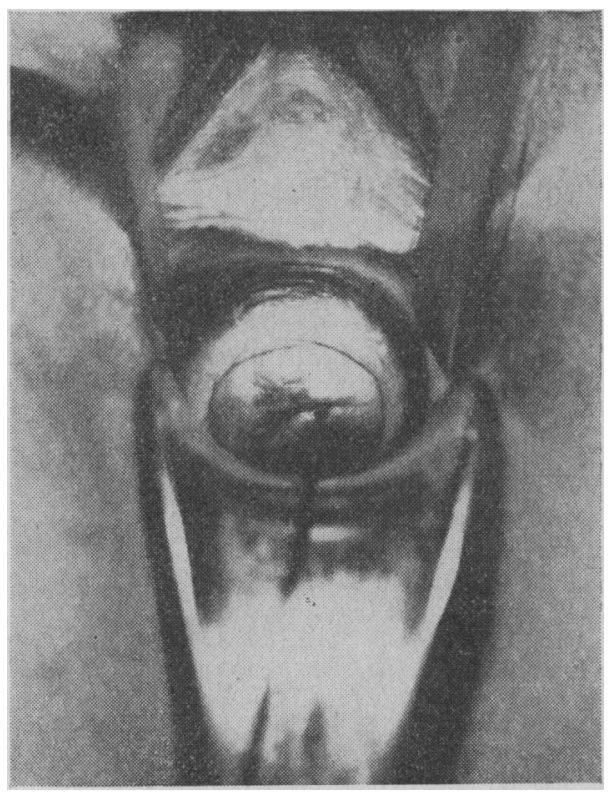

Typical case of cervical phimosis.

applying irritants to the vagina for oligomenorrhoea, infertility, or inducing abortion. This observation leads us to believe that a similar inflammatory reaction occurring during the intrauterine or immediate post-natal period may stimulate meso- dermal proliferation and formation of complete or incomplete vaginal septum at any level. When the septum occurs in the upper vagina it is recognized as phimosis of the cervix.

Kanagasuntheram and Dassanayake (1958) also consider the possibility of abnormal mesodermal proliferation as the causal factor, based on the analogy of development of similar septa in the intestines. The type of septum formed depends entirely on the site, direction, and extent of the mesodermal proliferation surrounding the developing vagina.

With regard to treatment the lateral incisions, one on each side, starting from the opening already present, were sufficient to restore the normal calibre of the vagina. Excision of the septum was not considered for fear of cicatrix causing dyspareunia.

\section{Summary}

Congenital cervical phimosis presenting as an incomplete septum just below the cervix, four examples of which are described, should be kept in mind when cases of dysmenorrhoea or dyspareunia are met with. The condition may also pose difficulties in an occasional case of labour by simulating cervical dystocia.

From an analogy of vaginal septa developing from chronic irritation in the vagina during the child-bearing period the probable origin of a congenital type may be presumed to arise from vaginal infection during intrauterine life. This may well be a starting-point for mesodermal proliferation.

A simple line of treatment such as bilateral incisions would be useful in most cases. However, cicatrization of some degree may be met with as a result of any attempt to excise the septum.

\section{REFERENCES}

Jeffcoate, T. N. A. (1957). Principles of Gynaecology, p. 145. Butterworth, London.

Kanagasuntheram, R., and Dassanayake, A. G. S. (1958). F. Obstet. Gynaec. Brit. Emp., 65, 487.

Monie, S. W., and Sigardson, L. A. (1950). Amer. F. Obstet. Gynec., 59, 696.

Rubin, I. C. (1944). Ibid., 47, 826

Warner, R. E., and Mann, R. M. (1955). Obstet. and Gynec., 6, 405.

\section{Medical Memoranda}

\section{Case of Extradural Haemorrhage Successfully Treated by Packing}

\section{Brit. med. F., 1964, 2, 31-32}

Packing the intracranial cavity is rarely employed in neurosurgery for fear of the brain injury it may produce if it is sufficient to stop brain haemorrhage. However, if packing is done in the extradural space then the brain is less likely to be damaged, and it is recognized that this may be the only course open to a surgeon inexperienced in neurosurgery or without coagulating diathermy apparatus (McKenzie, 1938 ; Gurdjian and Webster, 1942 ; King, 1943 ; Brock, 1960 ; Potter, 1961). In this way bleeding may be stemmed or time gained so that the patient can be transferred with greater safety to a neurosurgeon.

The authors mentioned above comment in general on the value of packing the extradural space when bleeding cannot be stopped by other means, but few cases specifically treated in this way are mentioned in the literature. Robinson (1958), in reviewing 16 cases of extradural haemorrhage, noted one case which was treated by packing. Reichert and Morrissey (1941) reported a case in which a venous extradural haemorrhage was treated by use of gauze packing. This was removed 18 hours after operation. Shortly after its removal bleeding recurred, a further operation was necessary, and the bleeding venous sinus was covered with muscle strips. Wharton (1901) described a case in which a sagittal sinus extradural haematoma was treated successfully by packing.

The present case is described because it is thought that the technique of packing warrants consideration if precise identification of the bleeding-points is not feasible.

\section{CASE REPORT}

A Maldivian fisherman aged about 40 was struck twice on the head with an oar by ancther fisherman at approximately 10 a.m. on 17 June 1962. He was brought to Gan, a Royal Air Force staging post on the southernmost atoll of the Maldive group of islands, from 